\title{
Recovery of Used Lubricating Oils - A Brief Review
}

\author{
José Carlos Oliveira Santos* \\ Department of Biology and Chemistry, University of Campina Grande, Brazil
}

*Corresponding author : José Carlos Oliveira Santos, Laboratory of Bio-fuels and Environmental Chemistry, Department of Biology and Chemistry, Federal University of Campina Grande, Brazil.

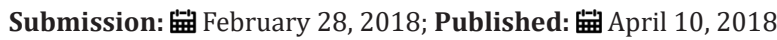

\begin{abstract}
Lubricating oils are substances of mineral or synthetic base responsible for forming a protective film, which prevents direct contact between two surfaces that move with each other. The lubricant mixture is formed by the addition of additives to the base oil obtained in the distillation of petroleum. When used oils are released directly into the environment or when uncontrolled burning causes serious soil, water and air pollution problems. Recycling the lubricant means applying physical-chemical processes on the used oil, making it possible to obtain base oil, a raw material that can be reused to obtain lubricants. The objective of the present work is to evaluate the recent processes of recovery of used automotive lubricating oils.
\end{abstract}

Keywords: Lubricating oils; Environment; Recycling

\section{Introduction}

Synthetic or non-synthetic lubricating oils are petroleum derivatives, used for automotive or industrial purposes, which after the recommended period of use recommended by the equipment manufacturers deteriorate in part, forming oxygenated compounds (organic acids and ketones), polynuclear aromatic compounds of high viscosity (and potentially carcinogenic), resins and lacquers [1]. In addition to the basic oil degradation products, there are present in the used oil the additives which have been added in the process of formulating these lubricants and which have not yet been consumed, wear metals of lubricated engines and engines and various contaminants such as water, fuel, dust and other impurities. The lubricating oil used may still contain chemicals which are sometimes unscrupulously added to the oil and its characteristic contaminants [2]. In this way, when waste oils are released directly into the environment (in water, sewage and soil networks) or when uncontrolled burning, they cause serious soil, water and air pollution problems. When released into the soil, the waste oils seep into the ground with the rainwater contaminating the soil they pass through, and when they reach underground groundwater, they also pollute the water from fountains and wells $[3,4]$. When discharged into wastewater drainage systems, they pollute water receiving facilities and also cause significant damage to wastewater treatment plants. The used oil contains high levels of hydrocarbons and metals [4], being the most representative iron, lead, zinc, copper, chromium, nickel and cadmium. The indiscriminate burning of the lubricating oil used, without prior treatment of demetallation, generates significant emissions of metallic oxides in addition to other toxic gases, such as dioxins and sulfur oxides.
Lubricating oils are among the few petroleum derivatives that are not fully consumed during use. Manufacturers of additives and formulators of this type of oil have been working on the development of products with longer life, which tends to reduce the production of waste oils. However, with the increase in additivation and the useful life of the oil, the difficulties in the regeneration process of the basic oil after use increase. On the other hand, if we look at the dangers that used oil can cause to the environment, a solution to the difficulties encountered would be easily justified. In addition, re-refining restores the conditions of the basic lubricating oil, whose quality is as good, as or even better than the basics of first refining. The refined oils would return to the market, generating jobs, saving foreign exchange and avoiding the increase of environmental pollution [5]. The introduction of the additives to the lubricants is intended to add to these important characteristics, such as dispersion or dispersivity, detergency inhibitor, antiwear, antioxidant, anticorrosive, antifoam, viscosity modifying, emulsifying, lowering pour point, tackiness etc. The amount of additives recommended by suppliers varies, on average, from 0.5 to $28 \%$ by volume. To formulate these additives, various chemicals are added to the base oil for the lubricant to perform well. In addition, the lubricating oil carries all kinds of impurities generated by the wear of the internal components. In this way, it is necessary to monitor the physicochemical properties of the lubricants used to determine the appropriate time to change them. Motor wear can be monitored through this characterization in waste oils. To achieve these goals, some techniques have been widely used to characterize lubricating oils and also in other petroleum derivatives $[3,6,7]$. 
Used oils, if disposed of in the soil, burned or discarded in water bodies, will cause strong environmental damage due to the high polluting potential [3]. Another great risk is when it reaches the ground; it becomes a kind of reservoir that will severely affect the subsoil and the water table, forming a plume of contamination, limiting the circulation of air through the soil particles, inhibiting the action of microorganisms and prevents access of plants to nutrients. The oils contain toxic metals from the additives as well as the wear of the engines, and contain in their composition polyaromatic hydrocarbons, such as benzopyrene, phenanthrene, fluorene, which are formed by oxidation processes during their useful life. Through the above we see how important it is to recycle this material that can be reused several times reducing the pollution of the environment [8].

Recycling the lubricant means applying physical-chemical processes on the used oil, making it possible to obtain base oil, a raw material that can be reused to obtain lubricants. The reuse of the oil is conditioned to the degree and type of contamination. The most common contaminants found in oils are: mild compounds (low boiling point), soluble compounds and insoluble compounds. Within the light compounds the most common are: water, gasoline and diesel. In the case of the soluble compounds all oxidized compounds and additives previously incorporated (antioxidants, detergents, dispersants) are highlighted, while the insoluble compounds comprise the oxidized hydrocarbons, particles and metal oxides $[5,8,9]$

In the case of lubricants, an alternative to their use after incineration is due to their high calorific value, however, since it is a material of non-renewable origin (base oils), it should not be used because it is highly polluting. Taking into account the fact that during its use the lubricant is not consumed, but its additives is that it loses its efficiency, recycling can be the most viable alternative not only technologically as well as economic and ecological. Some of the processes used in the recycling are of a physical nature, that is, they use only the different physical properties of the components to separate them. Others exist that employ chemical reactions to obtain products and the purification of the same ones [10-19].The processes employed can thus be described:

i. Sedimentation: It consists of leaving the used oil in a cuneiform bottom tank, without agitation, for a sufficient and adequate period of time. This method depends on the density of water, solid impurities and oil. Oxidized products that have the same oil density are not removed. Fluid oils separate from suspended matter more easily than viscous ones.

ii. Filtration: Consists of passing the oil through certain materials that retain the solid particles. Filtering devices are largely based on the principle of operation, cost and performance. Lately a lot of adsorbent filters have been used; the activated bauxite being widely used. The great problem of filtration efficiency is the presence of water in considerable quantities. Efficiency depends on the type of oil and the service. iii. Centrifugation: Centrifugal purification is a mechanical process by which the separation of impurities from liquids is accelerated, spinning at high peripheral speeds. It is an economical process for large volumes of oil. It does not remove additives and takes up small space. It is used successfully in the purification of the oils of air filters, hydraulic oils, motor oils.

iv. Degasification: It consists of a high vacuum chamber with an inlay containing small metal rings or ceramic pieces to obtain a large surface. This process is widely used in the drying of insulating oils. In this process, dissolved gases, as well as water and mixtures of solvents which may be present in the lubricant are withdrawn.

v. Thermal dehydration: Consists of passing the lubricating oil through a two-stage column operating independently. The first stage consists of heating the oil in the range of $160{ }^{\circ} \mathrm{C}$ to $200^{\circ} \mathrm{C}$ under normal pressure. The oil circulates in a continuous stream through a heat exchanger where a certain amount of dehydrated oil is removed to the second stage at the top of the column and cooled. The water and the light fractions are removed.

vi. Solvent extraction: It is a very useful process as it can be used for any type of paraffinic oil. It consists in separating, by solubility difference, paraffinic and naphthenic compounds from undesirable compounds such as sludge, resins and asphalt compounds. The process is capable of removing about $10-14 \%$ of the contaminants, which corresponds to approximately the amount of additives and impurities normally found in the lubricating oil used. In this process, two parameters are critical to the success of the recovery, the ratio (solvent: lubricant used) and the extraction temperature, where these must be chosen to be able to remove impurities and additives and decrease the base oil loss.

vii. Acid treatment: The use of sulfuric acid in the treatment of waste oils. The acid attacks the unsaturated hydrocarbons producing esters, alcohols, polymers and oxidized products. This treatment allows the deposition of sludge after a decanting step.

viii. Neutralization: A process that aims to neutralize the excess of acid or base present in the medium converting into salts. At this stage the $\mathrm{pH}$ of the solution is adjusted to approximately 7. It consists of adding caustic soda or potash to the oil. This treatment is done in a bottom tank equipped with a reactor.

ix. Hydrofination: consists of hydrogenolysis, where hydrogen acts under high pressure on unstable hydrocarbons. Hydrogen acts to saturate unstable hydrocarbons. In addition to improving the color, a better oxidation resistance and a reduction of the carbon residue is obtained.

x. Fractional distillation: it consists of separating by strip of distillation the mixture that constitutes the used oil. Steam extraction is used to increase the flash point of most heavy 
oils where hot oil is placed in contact with the steam in an extraction tower. Vacuum distillation is indicated to reduce a residual stock of asphalt and by-products, in the distillation of crude oil, in the production of low-carbon oils. Some work has been done on the determination of metals and other contaminants in lubricating oils $[14,16,20]$. However, works that recovers used lubricating oils and make their chemical and physicochemical characterization relating these properties to those found in new lubricating oils has been poorly reported [21-23]. From the above, it is highly relevant that this raw material is regenerated through cleaner technology, providing protection to the environment, avoiding waste and promoting an intelligent use of natural resources.

\section{Conclusion}

The indiscriminate disposal of the lubricating oil harms the environment and misses a promising source of resources and, therefore, it is necessary to develop technologies for its recovery. Recycling becomes the proper treatment of the used oil, through specific processes, thus allowing the reuse of the same. Various recycling alternatives have been used around the world for recovery of used lubricating oil, each with its advantages and disadvantages. Recycled engine oil can be burned as fuel, usually in boilers, plant heaters or for industrial heating applications such as furnaces and cement kilns. Recycled oil is distilled in diesel fuel or marine fuel, in a process similar to refining. The lubricating property of the engine oil persists even with used and can be recycled indefinitely. Thus, the recycling of used lubricating oils can gain more and more space in the context of environmental conservation.

Regeneration or re-treatment treatments are processes to produce basic oils. There are several technologies on the market, but in common are pre-treatment, cleaning, fractionation and final treatment of waste oils. In general, the different processes of regeneration of lubricating oils are applied as a function of the level of degradation suffered by the oil, where it passes through the processes of fluid withdrawal, viscosity correction, filtering and separation of particulates, chemical additives specified according to standards established by law.

\section{References}

1. Santos JCO, Souza AG, Santos IMG, Sobrinhoc EV, Fernandes VJ, et al. (2004) Thermoanalytical and rheological characterization of automotive mineral lubricants after thermal degradation. Fuel 83(17-18): 23932399.

2. Santos JCO, Santos IMG, Souza AG (2015) Thermal degradation process of synthetic lubricating oils: Part I - Spectroscopic Study. Petrol Sci Technol 33(11): 1238-1245.

3. Park SW, Lee JY, Yang JS, Kim KJ, Baek K (2009) Electrokinetic remediation of contaminated soil with waste-lubricant oils and zinc. J Hazard Mater 169(1-3): 1168-1176.

4. Santos JCO, Souza AG, Oliveira AD, Lima LN, Silva CC, et al. (2007) Kinetic and activation thermodynamic parameters on thermal decomposition of synthetic lubricant oils. J Therm Anal Calorim 87(3): 823-829.
5. Al Ghouti MA, Al Atoum L (2009) Virgin and recycled engine oil differentiation: A spectroscopic study. J Environ Manag 90(1): 187-195.

6. Tsai WT (2011) An analysis of used lubricant recycling, energy utilization and its environmental benefit in Taiwan. Energy 36(7): 4333-4339.

7. Santos JCO, Souza AG (2006) Liquid specific heat capacity of motor lubricant oils after thermal degradation. J Eng Applied Sci 1(3): 495-499.

8. Santos JCO, Almeida RA, Carvalho MWNC, Conceição MM, Souza AG (2014) Avaliação da estabilidade térmica e oxidativa de óleo lubrificante automotivo recuperado usando o solvente metiletilcetona. Química No Brasil 8(2): 49-56.

9. Lima AEA, Conceicão MM, Santos JCO,Rosenhaim R, Santos IMG, et al (2016) Otimização do processo de recuperação de lubrificante usado por extração com solventes polares. Rev Quím Ind 84: 57-66.

10. Hamad A, Al Zubaidy E, Fayed ME (2005) Used lubricating oil recycling using hydrocarbon solvents. J Environ Manag 74(2): 153-159.

11. Rincón J, Cañizares P, Gracía MT (2007) Regeneration of used lubricant oil by ethane extraction. The Journal of Supercritical Fluids 39(3): 315322.

12. Lam SS, Russel AD, Chase HA (2010) Microwave pyrolysis, a novel process for recycling waste automotive engine oil. Energy 35(7): 29852991.

13. Majano G, Mintova S (2010) Mineral oil regeneration using selective molecular sieves as sorbents. Chemosphere 78(5): 591-598.

14. Menzel K, Lindner J, Nirchl H (2012) Removal of magnetite particles and lubricant contamination from viscous oil by high-gradient magnetic separation technique.Sep Purif Technol 92(18): 122-128.

15. Al Zahrani SM, Putra MD (2013) Used lubricating oil regeneration by various solvent extraction techniques. J Ind Eng Chem 19(2): 536-539.

16. Kanokkantapong V, Kiatkittipong W, Panyapinyopol B, Wongsuchoto $\mathrm{P}$, Pavasant P (2009) Used lubricating oil management options based on life cycle thinking. Resour Conserv Recycl 53(5): 294-299.

17. Lima AEA, Sales HB, Lima LC, Santos JCO, Santos IMG, et al. (2017) Natural clay applied to the clarification of used automotive lubricating oil. Cerâmica 63 (368): 517-523.

18. Santos JCO, Santos IMG, Souza AG (2017) Thermal degradation of synthetic lubricating oils: Part II - Rheological study. Petrol Sci Technol 35(6): 535-539.

19. Santos JCO, Santos IMG, Souza AG (2017) Thermal degradation of synthetic lubricating oils: Part III - TG and DSC studies. Petrol Sci Technol 35(6): 540-546.

20. Watcharasing S, Kongkowit W, Chavadej S (2009) Motor oil removal from water by continuous froth flotation using extended surfactant: Effects of air bubble parameters and surfactant concentration. Sep Purif Technol 70(2): 179-189.

21. Santos JCO, Santos IMG, Souza AG, Sinfrônio FSM, Silva MA, et al. (2005) Thermodynamic and kinetic parameters on thermal degradation of automotive mineral lubricant oils determined using thermogravimetry. J Thermal Anal Calorim 79(2): 461-467.

22. Santos JCO, Santos IMG, Souza AG (2006) Kinetic on thermal decomposition reactions of mineral lubricant oils by thermogravimetry. Res J Applied Sci 1(1): 7-10.

23. Santos JCO, Santos IMG, Souza AG, Lima LN (2007) Thermal, spectroscopic and rheological study of mineral base lubricating oils. J Therm Anal Calorim 87(3): 639-643. 
Creative Commons Attribution 4.0 International License

For possible submissions Click Here

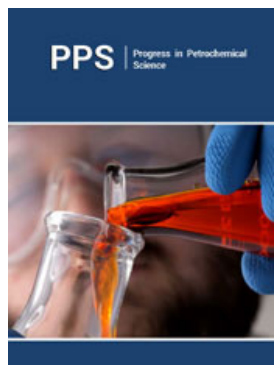

\section{Progress in Petrochemical Science \\ Benefits of Publishing with us}

- High-level peer review and editorial services

- Freely accessible online immediately upon publication

- Authors retain the copyright to their work

- Licensing it under a Creative Commons license

- Visibility through different online platforms 